\title{
ИСПОЛЬЗОВАНИЕ ПОБОЧНЫХ ПРОДУКТОВ ПЕРЕРАБОТКИ ЦЕЛЛЮЛОЗЫ В КРАШЕНИИ ШЕРСТИ ХРОМОВЫМИ КРАСИТЕЛЯМИ
}

\section{(C) С.В. Смирнова}

\author{
Ивановский государственный химико-технологический университет, \\ Шереметьевский пр., 7, Иваново, 153000 (Россия), \\ e-mail: smirnovasv1961@mail.ru
}

В работе изучалась возможность совершенствования процесса хромирования при крашении шерстяного волокна хромовыми красителями с помощью побочных продуктов переработки целлюлозы - лигносульфонатов различных марок, используемых для повышения степени полезного использования хромирующего реагента Cr (VI). Иx присутствие в красильных ваннах в 5-6 раз повышает скорость восстановления Cr (VI) и в 2-3 раза повышает скорость реакции комплексообразования. Установленные закономерности позволяют не только интенсифицировать процесс крашения, но и в 4-5 раз снизить количество Cr (VI) в остаточных ваннах, а также предохранить шерсть от повреждения на стадии хромирования

Ключевые слова: лигносульфонаты, бихромат калия, комплексообразование, шерстяное волокно, хромовые красители.

\section{Введение}

Утилизация отходов лесоперерабатывающей промышленности относится к числу важнейших экологических проблем настоящего времени. Один из наиболее экологически вредных древесных отходов гидролизованный лигнин. Внедрение большинства разработанных на сегодняшний день технологий его утилизации или глубокой переработки сдерживается требованиями больших капитальных и эксплуатационных затрат, квалифицированных кадров, сложного оборудования [1]. Доля используемых промышленных лигнинов пока еще невысока. Из ежегодно выделяемых из растительного сырья более чем 50 млн т лигнина для различных практических целей используется немногим более 1 млн т. В промышленности выделение лигнина из древесины и других растений осуществляется в процессах получения целлюлозы при сульфатной и сульфитной варках [2]. Основными используемыми лигнинными продуктами являются сульфитные лигнины (лигносульфонаты). Наибольшую привлекательность имеют технологии прямого использования лигносульфонатов технических (ЛСТ) (побочных продуктов варки целлюлозы сульфитным способом) без дополнительной переработки.

На основании ранее проведенных исследований по применению ЛСТ в подготовке шерсти к крашению [3] можно предположить, что применение лигносульфонатов в хромовом крашении позволит снизить повреждение кератина шерсти. Во-первых, ЛСТ, являющиеся анионактивными многофункциональными полимерами, хорошо адсорбируются поверхностью волокна, создавая стерические помехи разрущающему воздействию сильного окислителя - бихромата калия. Во-вторых, ЛСТ содержат соединения, обладающие легкими восстановительными свойствами: ксилозу, арабинозу, глюкозу и другие сахара [6] - это тоже должно способствовать защите волокна от окислительного разрушения.

Дополнительное преимущество использования подобного слабого восстановителя состоит в возможности снижения токсичности сточных вод за счет более полного протекания перехода хрома из шести-

Смирнова Светлана Викторовна - старший научный сотрудник кафедры «Химическая технология волокнистых материалов», кандидат технических наук, доцент, e-mail: smirnovasv1961@ mail.ru валентного в трехвалентное состояние. Хром относится к металлам, токсическое воздействие которого на человека зависит от степени его окисления. Соединения шестивалентного хрома значительно ток- 
сичней соединений трехвалентного. Подобный комплексный экологический эффект (утилизация отходов переработки целлюлозы плюс снижение вредных выбросов в шерстяной отрасли) не должен снижать технологических параметров крашения. Оптимальным вариантом следует признать такой, который позволит наряду с экологическими одновременно решать и некоторые технологические задачи.

В процессе крашения на стадии хромирования происходит взаимодействие хромовых красителей с комплексообразователем, роль которого играет ион хрома (III). Ион трехвалентного хрома может быть введен в красильную ванну в форме соли хрома (III) или образовываться в результате восстановления из солей хрома (VI). Проведенные нами исследования убедительно показали, что наиболее эффективный хромирующий агент - бихромат калия. В процессе крашения шерсти на стадии хромирования происходит восстановление хрома (VI) до трехвалентного состояния; катионы $\mathrm{Cr}$ (III) образуют комплексы с хромофорами красителей $[4,5]$.

Наиболее простой и экономически выгодной является модернизация стадии хромирования или процесса крашения в целом.

Таким образом, цель настоящего исследования состояла в совершенствовании стадии хромирования процесса крашения шерсти хромовыми красителями, основанном на применении препаратов, ускоряющих реакцию окисления бихромата калия и повышающих степень связывания ионов трехвалентного хрома волокном и красителем, - лигносульфонатов.

\section{Экспериментальная часть}

В качестве объектов исследования выбраны технические лигносульфонаты различных марок (А, Б, В, Д и Е), обладающие во многом сходными физико-химическими параметрами и различающиеся, главным образом, катионом варочной кислоты (аммония, натрия, кальция) и редуцирующей способностью. Содержание редуцирующих веществ, например в ЛСТ натрия (м. Е) - 12\% (ОСТ 13-183-83, ТУ-13-0281036-029-94).

В исследовании использовались красители, относящиеся к основным группам класса хромовых: $o, o^{\prime}$-диоксиазокраситель - хромовый синий 2 К, оксикарбоксиазокраситель - бордо $\mathrm{C}$, антрахиноновый зеленый антрахиноновый, производный салициловой кислоты - оранжевый. Красители предварительно очищались по методике [6], степень чистоты, определенная методом элементного анализа, составляла 97,5\%. В работе использовались: бихромат калия («ч.д.а.»), уксусная кислота («х.ч.»), уксуснокислый натрий («Х.ч.»).

Обработке подвергалась шерстяная гребенная лента марок: помесная союзная 60к и австралийский меринос 64к, подготовленная к крашению в производственных условиях.

Процесс крашения шерстяного волокна осуществлялся периодическим способом по следующему температурно-временному режиму: крашение начиналось при $40{ }^{\circ} \mathrm{C}$ в течение 20 мин, затем температура поднималась до $96{ }^{\circ} \mathrm{C}$ в течение 20 мин. Следующие 60 мин волокно красилось при этой температуре. Далее добавлялся бихромат калия и волокно обрабатывалось в течение 30 мин, после чего тщательно промывалось. При этом обеспечивалась постоянная циркуляция красильного раствора через контейнер с волокном. Кислотность растворов поддерживалась буфером, приготовленным по методике Бриттона [7], в интервале значений 4,05-4,45 и контролировалась с точностью до $\pm 0,05$ единиц прибором pH-метром - милливольтметром $\mathrm{pH}-121$.

Контроль за изменением концентрации красителя осуществлялся спектрофотометрическим методом при длинах волн, соответствующих максимуму поглощения исследованных красителей. Содержание бихромат-ионов в хромировочной ванне определялось посредством дифенилкарбазидного метода [8]. Кинетика реакции комплексообразования исследовалась при температурах 70, 80, 90 и $98{ }^{\circ} \mathrm{C}$ (кювета с раствором помещалась в термостатированную ячейку). Обработка кинетической информации осуществлялась методами, принятыми в формальной кинетике.

Оценка колористических характеристик проводилась спектрофотометрическим методом. Для этого снимались спектры отражения образцов окрашенного волокна на спектрофотометре СФ-18.

Величина $K / S$, характеризующая интенсивность окраски текстильного материала, определялась по формуле Гуревича-Кубелки-Мунка [9]:

$$
\frac{K}{S}=\frac{(1-R)^{2}}{2 R}
$$

где $\mathrm{R}$ - коэффициент диффузного рассеяния света, $\mathrm{K}$ - коэффициент поглощения света, $\mathrm{S}$ - коэффициент рассеяния света. 
Неровнота окраски рассчитывалась с использованием системы $C I E L^{*} a^{*} b^{*}$, путем расчета среднеквадратичного отклонения между цветовыми различиями $\Delta E$ по измерениям в пяти точках на каждый образец [9].

Для оценки степени повреждения волокна проводились динамометрические измерения разрывной нагрузки штапельков волокна на приборе ДШ-314-2.

\section{Обсуждение результатов}

В работе исследовано влияние добавок лигносульфонатов различных марок на кинетику процесса комплексообразования в растворах хромовых красителей, на процесс восстановления шестивалентного хрома и на технологические характеристики окрашенного волокна.

На рисунке приведены кинетические кривые, описывающие изменение концентрации бихроматионов в растворе при $90{ }^{\circ} \mathrm{C}$ для красителей, отличающихся структурой молекул. Оказалось, что химическое строение красителей не оказывает существенного влияния на кинетику восстановления шестивалентного хрома - изменение во времени содержания хрома в виде бихромат-ионов в растворах выбранных групп фактически может быть описано одной кривой с чрезвычайно малыми отклонениями.

Из рисунка видно, что в присутствии лигносульфоната реакция комплексообразования значительно ускоряется: максимальный выход комплексного соединения достигается уже после 15-20 мин взаимодействия. Состояние равновесия в системе хромовый краситель - бихромат калия - лигносульфонат достигается через 30-40 мин против 90-100 мин без ЛСТ. Что особенно важно, в присутствии ЛСТ остаточное (равновесное) содержание $\mathrm{Cr}(\mathrm{VI})$ снижается в среднем примерно в 3 раза.

Взаимодействие бихромата калия с исследованными красителями хорошо описывается уравнением для реакции первого порядка по иону хрома. Это подтверждается линейностью зависимости логарифма концентрации красителя $C_{\tau}$ от времени протекания реакции. По экспериментальным данным кинетики рассчитаны эффективные константы скорости процесса комплексообразования $\left(K_{\text {эфф }}\right)$ по уравнению:

$$
K_{\ni \phi \phi}=\frac{2,3}{\tau} \lg \frac{C_{0}}{C_{\tau}}
$$

где $K_{\text {эфф }}$ - эффективная константа скорости процесса; $\tau$ - длительность процесса, мин; $C_{0}, C_{\tau}-$ соответственно начальная и текущая концентрации хромирующего агента.

Рассчитанные значения для одного из исследуемых красителей приведены в таблице 1.

Анализируя данные таблицы, можно отметить, что с повышением температуры на каждые $10{ }^{\circ} \mathrm{C}$ значение $K_{\text {эфф. }}$ возрастает в 1,5-3 раза. В присутствии лигносульфонатов процесс образования хромовых комплексов существенно ускоряется - значения $K_{\text {эфф. }}$ возрастает примерно в 1,5 раза, что связано с редуцирующей способностью лигносульфонатов. ЛСТ являются более сильным восстановителем, чем краситель, и реакция перехода хрома в трехвалентное состояние протекает за счет окисления функциональных групп ЛСТ. Таким образом, помимо ускоряющего воздействия на процесс комплексообразования лигносульфонаты выполняют роль защитного агента, ограждающего краситель от разрушения.

Зависимость содержания бихромат-ионов в растворе от длительности реакции бихромата калия с красителями зеленым антрахиноновым (1, $6)$, ярко-красным $(2,5)$, оранжевым $(3,4): 1-3$ - без ЛСТ; 4-6 - концентрация ЛСТ 2,5 г/л

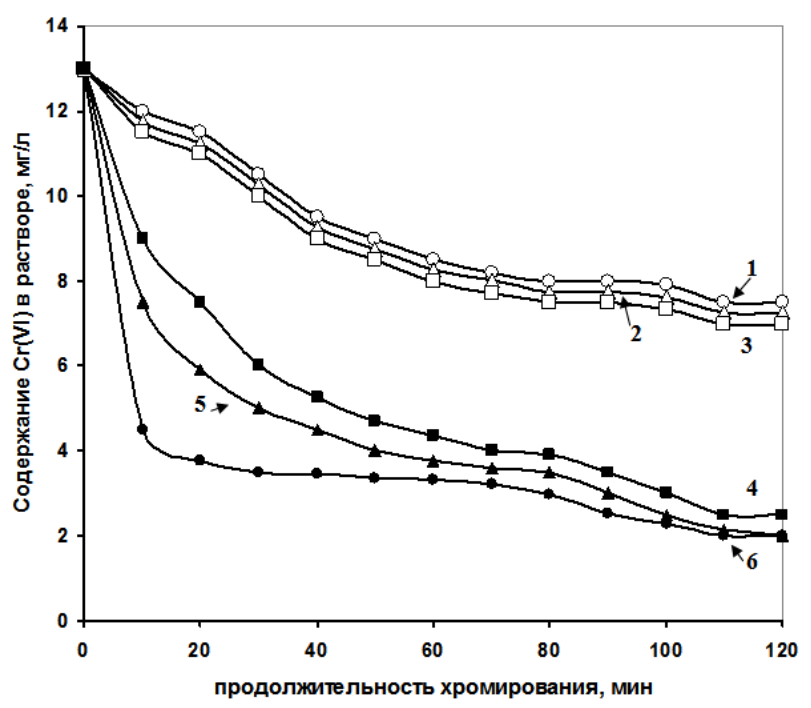


Таблица 1. Эффективные константы скорости реакции комплексообразования красителя хромового синего 2К в присутствии различных ЛСТ

\begin{tabular}{l|c|c|c|c}
\hline \multicolumn{1}{c|}{\begin{tabular}{c} 
Хромирующий \\
\multicolumn{1}{c|}{ состав }
\end{tabular}} & $70{ }^{\circ} \mathrm{C}$ & $80{ }^{\circ} \mathrm{C}$ & $90{ }^{\circ} \mathrm{C}$ & $98{ }^{\circ} \mathrm{C}$ \\
\cline { 2 - 5 } & 0,520 & 1,010 & 1,535 & 2,675 \\
$\mathrm{~K}_{2} \mathrm{Cr}_{2} \mathrm{O}_{7}$ & 0,750 & 1,213 & 2,405 & 4,242 \\
$\mathrm{~K}_{2} \mathrm{Cr}_{2} \mathrm{O}_{7}$ в присутствии ЛСТ натрия (м.А) & 0,727 & 1,183 & 1,921 & 3,800 \\
$\mathrm{~K}_{2} \mathrm{Cr}_{2} \mathrm{O}_{7}$ в присутствии ЛСТ натрия (м.Е) & 0,676 & 1,084 & 1,611 & 3,254 \\
$\mathrm{~K}_{2} \mathrm{Cr}_{2} \mathrm{O}_{7}$ в присутствии ЛСТ натрия (м.В) & &
\end{tabular}

В процессе крашения шерсти хромовыми красителями восстановление хрома до трехвалентного состояния происходит не только за счет окисления красителя, но и, главным образом, при взаимодействии бихромат-ионов с соответствующими группами кератина шерсти. Восстановление шестивалентного хрома происходит в несколько стадий, каждая из которых сопровождается повреждением кератина [10]:

- восстановление шестивалентного хрома до четырехвалентного происходит с одновременным окислением групп цистина в шерсти;

- четырехвалентный хром восстанавливается до двухвалентного с одновременным окислением цистиновых и тиразиновых групп шерсти; затем двухвалентный хром реагирует с карбоксильными группами шерсти;

- комплекс двухвалентный хром - карбоксил самопроизвольно окисляется, давая комплекс трехвалентный хром - карбоксил.

Проблемам предохранения шерсти при обработке хромировочными растворами и снижения содержания хрома в стоках исследователи уделяют особое внимание. В работе [11] рекомендуется для более успешного проведения процесса хромирования использовать добавки муравьиной кислоты и сульфата натрия или одной только муравьиной кислоты. Полезно также введение фосфата натрия и молочной кислоты: молочная кислота, являясь слабым восстановителем, защищает кератин от окисления. Вместо молочной кислоты можно применять миндальную [10].

Ускорить восстановление хрома до трехвалентного состояния позволяет добавка продуктовкомплексообразователей (щавелевой или салициловой кислот, глицерина) [10]. Кроме того, образование комплексов $\mathrm{Cr}^{3+}$ с органическими соединениями препятствует возникновению малоактивных гидратированных ионов хрома, что способствует ускорению процесса.

Введение восстановителя - тиосульфата натрия в хромировочную ванну в количестве на $10 \%$ большем, чем содержание бихромата калия, способствует быстрому восстановлению $\mathrm{Cr}^{6+}$ до $\mathrm{Cr}^{3+}$, улучшает поглощение ионов хрома волокном. Это позволяет проводить процесс хромирования при пониженной температуре, но снижает воспроизводимость окраски и ограничивает ассортимент применяемых красителей.

С целью предохранения кератина шерсти от окисления его солями хрома на стадии хромирования, с одной стороны, возможно применение восстановителя, существенно превышающего по восстанавливающей способности кератин (термодинамический подход). С другой стороны, необходимо ТВВ, хорошо «укрывающее» кератин за счет эффективной адсорбции и создающее чисто стерические, механические помехи контакту кератина с окислителем (кинетический подход). Реальное сочетание обоих подходов применение слабого восстановителя, обладающего сродством к шерсти.

Ранее проведенные исследования показали, что ЛСТ обладают достаточно высоким сродством к шерстяному волокну, что видно из анализа кинетики их адсорбции шерстью из растворов [3, 4]. Установлено, что наряду с ионным взаимодействием ЛСТ с шерстью (в силу строения ЛСТ - большой протяженностью их основных цепей) большое значение имеет адсорбция посредством водородных связей и Вандер-Ваальсовых взаимодействий основной цепи молекулы ЛСТ и кератина. Образующийся в исследованных условиях монослой адсорбированных молекул ЛСТ «укрывает» сорбционно-доступную поверхность волокна. Это позволяет использовать ЛСТ в качестве защитных агентов на всех стадиях отделки шерстяного волокна. С целью оценки относительной восстановительной способности ЛСТ были измерены их окислительно-восстановительные потенциалы.

Результаты измерений приведены в таблице 2 в порядке снижения восстановительной способности ЛСТ. Здесь же приведены окислительно-восстановительные потенциалы моделирующих кератин аминокислот DL-лизина солянокислого и L-гистидина солянокислого, а также муравьиной и молочной кислот, 
часто предлагаемых в качестве восстановителей шестивалентного хрома для предохранения волокна от повреждения в процессе хромирования.

Как видно из представленных в таблице 2 данных, ЛСТ обладают значительно большей восстановительной способностью, чем молочная и муравьиная кислоты (в 1,5-2 раза) и, самое главное, - аминокислоты. Следовательно, при добавлении в красильную ванну сильного окислителя (бихромата калия) в первую очередь пойдет окисление функциональных групп ЛСТ, а не кератина шерсти. Вместе с тем окислительно-восстановительные потенциалы ЛСТ не настолько велики, чтобы они могли вызывать восстановительную деструкцию волокна.

Установленные закономерности послужили основой для создания интенсифицированной малоотходной и экологически более чистой технологии крашения шерсти хромовыми красителями (табл. 3).
Таблица 2. Окислительно-восстановительные потенциалы растворов ЛСТ различных марок

\begin{tabular}{l|c}
\hline \multicolumn{1}{c|}{ Наименование агента } & $\varphi$, В \\
\hline ЛСТ натрия (марка А) & 0,335 \\
ЛСТ натрия (марка Е) & 0,379 \\
ЛСТ кальция (марка В) & 0,383 \\
ЛСТ натрия (марка Б) & 0,385 \\
ЛСТ аммония (марка В) & 0,385 \\
ЛСТ аммония (марка Д) & 0,425 \\
ЛСТ натрия (марка В) & 0,520 \\
DL-лизин солянокислый & 0,575 \\
L-гистидин солянокислый & 0,628 \\
Молочная кислота & 0,663 \\
Муравьиная кислота & 0,694 \\
\hline
\end{tabular}

Таблица 3. Влияние ЛСТ на технологические параметры процесса крашения и характеристики окрашенного волокна

\begin{tabular}{|c|c|c|c|c|c|}
\hline $\begin{array}{c}\text { Технология } \\
\text { крашения }\end{array}$ & $\begin{array}{c}\text { Эффективные константы } \\
\text { скорости крашения } \\
\mathrm{K}_{\text {эфф. }} 10^{3} \text { мин }^{-1} \\
\end{array}$ & $\begin{array}{c}\text { Интенсивность } \\
\text { окраски, } K / S\end{array}$ & $\begin{array}{l}\text { Цветовое раз- } \\
\text { личие, } \Delta \mathrm{E}, \text { ед }\end{array}$ & $\begin{array}{c}\text { Степень повре- } \\
\text { ждения ШВ, про- } \\
\text { цент от исходной }\end{array}$ & $\begin{array}{l}\text { Содержание } \\
\text { остаточного } \\
\mathrm{Cr}(\mathrm{VI}), \text { мг/л }\end{array}$ \\
\hline \multicolumn{6}{|c|}{ Хромовый ярко-красный } \\
\hline I & $3,25 \pm 0,50$ & 12,58 & 3,93 & 15,0 & 0,60 \\
\hline II & $4,97 \pm 0,60$ & 14,59 & 2,37 & 9,6 & 0,25 \\
\hline \multicolumn{6}{|c|}{ Хромовый зеленый антрахиноновый } \\
\hline I & $2,83 \pm 0,10$ & 7,11 & 3,29 & 14,5 & 0,63 \\
\hline II & $6,75 \pm 0,15$ & 7,80 & 2,38 & 10,0 & 0,20 \\
\hline \multicolumn{6}{|c|}{ Хромовый синий 2К } \\
\hline $\mathrm{I}$ & $5,14 \pm 0,40$ & 8,20 & 14,6 & 0,72 & 0,62 \\
\hline II & $7,12 \pm 0,15$ & 9,66 & 10,4 & 0,27 & 0,23 \\
\hline \multicolumn{6}{|c|}{ Хромовый оранжевый } \\
\hline I & $3,43 \pm 0,20$ & 5,82 & 3,71 & 14,9 & 0,67 \\
\hline II & $4,92 \pm 0,10$ & 6,45 & 1,45 & 9,8 & 0,30 \\
\hline
\end{tabular}

"Примечание: I - типовая технология, II -крашение и хромирование с ЛСТ (м.Е)

\section{Выводы}

Использование лигносульфонатов в процессе крашения шерстяного волокна хромовыми красителями существенно повышает скорость крашения (в 1,3-3,5 раза), равномерность окрасок (в 1,6-3,4) раза, увеличивает выход красителя на волокно (на 4-5\%), а также позволяет снизить потери прочности шерстяного волокна в процессе хромирования. Кроме того, разработанная технология позволяет в 4-5 раз снизить количество Cr (VI) в остаточных ваннах и улучшить экологическую обстановку в районах целлюлознобумажных комбинатов.

\section{Сиисок литературы}

1. Беловежец Л.А., Волчатова И.В., Медведева С.А. Перспективные способы переработки вторичного лигноцеллюлозного сырья // Химия растительного сырья. 2010. №2. С. 5-16.

2. Дейнеко И.П. Утилизация лигнинов: достижения, проблемы и перспективы // Химия растительного сырья. 2012. №1. С. 5-20.

3. Смирнова С.В., Леднева И.А., Лосева Л.П. Механизм защитного действия лигносульфонатов в процессе карбонизации шерстяного волокна // Известия вузов Технология текстильной промышленности. 1997. №4. С. 55-57.

4. Смирнова С.В., Леднева И.А., Мельников Б.Н., Кочергин А.Б. Влияние лигносульфонатов на состояние хромовых красителей в растворе // Текстильная химия. 1998. №1. С. 28-32.

5. Смирнова С.В. Комплексообразование в растворах хромовых красителей // Журнал прикладной химии. 2012. T. 85, №4. C. 542-545. 
6. Корчагин М.В., Соколова Н.М., Шиканова И.А. Лабораторный практикум по химической технологии волокнистых материалов. М., 1976. С. 235-236.

7. Бриттон Х.Т.С. Водородные ионы. Л., 1936. 215 с.

8. Лурье Ю.Ю. Унифицированные методы анализа сточных вод. М., 1971. С. 302-305.

9. Методы исследования в текстильной химии : справочник / под ред. Г.Е. Кричевского. М., 1993. 401 с.

10. Новорадовская Т.С., Садова С.Ф. Химия и химическая технология шерсти. М., 1986. 199 с.

11. Duffield P.A., Hoppen K.H. Chrom dyes for wool // Text. Asia. 1987. Vol. 18, N3. Pp. 78-81.

Поступило в редакцию 13 декабря 2012 2. WOOL FIBER

Ivanovo State University of Chemical Technology, Sheremet'evskii ave., 7, Ivanovo, 153000, (Russia), e-mail: smirnovasv1961@mail.ru

Application of cellulose processing by-products (lignin sulfonates) appeared to be high-effective for the chroming process in the wool fiber dyeing. Lignin sulfonates show affinity to wool. They have higher reductivity than keratin and chrome dyestuffs. Addition of lignin sulfonates to the dyeing baths increases the dyeing speed (1,3-1,5 times), increases the evenness of the dyeing (1,6-3,4 times), increases colour yield (by 4-5\%) and decreases the tensile strength losses of the wool fiber. The developed dyeing process leaves 4-5 times less residual $\mathrm{Cr}$ (VI) in the dyeing baths, and utilizes cellulose processing byproducts - that works for ecological improving of both wool dyeing and cellulose processing.

\section{References}

1. Belovezhets L.A., Volchatova I.V., Medvedeva S.A. Khimiia rastitel'nogo syr'ia, 2010, no. 2, pp. 5-16. (in Russ.).

2. Deineko I.P. Khimiia rastitel'nogo syr'ia, 2012, no. 1, pp. 5-20. (in Russ.).

3. Smirnova S.V., Ledneva I.A., Loseva L.P. Izvestiia vuzov Tekhnologiia tekstil'noi promyshlennosti, 1997, no. 4, pp. 55-57. (in Russ.).

4. Smirnova S.V., Ledneva I.A., Mel'nikov B.N., Kochergin A.B. Tekstil'naia khimiia, 1998, no. 1, pp. 28-32. (in Russ.).

5. Smirnova S.V. Zhurnal prikladnoi khimii, 2012, vol. 85, no. 4, pp. 542-545. (in Russ.).

6. Korchagin M.V., Sokolova N.M., Shikanova I.A. Laboratornyi praktikum po khimicheskoi tekhnologii voloknistykh materialov. [Laboratory workshop on chemical technology of fibrous materials.]. Moscow, 1976, pp. 235-236. (in Russ.).

7. Britton Kh.T.S. Vodorodnye iony. [Hydrogen ions]. Leningrad, 1936, 215 p. (in Russ.).

8. Lur'e Iu.Iu. Unifitsirovannye metody analiza stochnykh vod. [Standardized methods for analysis of wastewater.]. Moscow, 1971, pp. 302-305. (in Russ.).

9. Metody issledovaniia v tekstil'noi khimii: Spravochnik. Ed. G.E. Krichevskii [Research Methods in Textile Chemistry: Handbook. Ed. G.E. Krichevskii.]. Moscow, 1993, 401 p. (in Russ.).

10. Novoradovskaia T.S., Sadova S.F. Khimiia i khimicheskaia tekhnologiia shersti. [Chemistry and chemical technology of wool.]. Moscow, 1986, 199 p. (in Russ.).

11. Duffield P.A., Hoppen K.H. Text. Asia, 1987, vol. 18, no. 3, pp. 78-81. 